\title{
Novos diálogos dos estudos feministas da deficiência
}

\author{
Ruthie Bonan Gomes \\ Paula Helena Lopes \\ Marivete Gesser \\ Maria Juracy Filgueiras Toneli
}

\section{$-2$}

Resumo: O objetivo deste estudo foi o de caracterizar a produção recente dos estudos feministas da deficiência (Feminist disability studies), com o foco na intersecção entre gênero e deficiência. Para tanto, foi realizada uma revisão da literatura internacional na qual foram incluídos artigos publicados nos últimos cinco anos em revistas disponíveis no portal de periódicos da CAPES. Os artigos analisados ressaltam que os modelos de compreensão da deficiência têm efeitos sociais e políticos nas formas de se pensar em questões como a corporeidade, a sexualidade, o cuidado e a interdependência. Além disso, as produções estudadas apontam que a inclusão da deficiência como categoria de análise a ser considerada nos estudos e práticas sociais tem um potencial analítico e político.

Palavras-chove: feminist disability studies; gênero; deficiência; interseccionalidade

New Dialogues in Feminist Disability Studies

Abstract: This study aimed to characterize the recent production of feminist disability studies, focusing on the intersection between gender and disability. Therefore, a review of the international literature was carried out, in which articles published in the last five years in journals available in the CAPES journal portal were included. The analyzed articles emphasize that the models of understanding disability have social and political effects in the ways of thinking about issues such as corporeality, sexuality, care and interdependence. Moreover, the studied productions point out that the inclusion of disability as a category of analysis to be considered in studies and social practices has an analytical and political potential.

Keywords: Feminist Disability Studies; Gender; Disability; Intersectionality

\section{A deficiência e seus percursos conceituais e teóricos}

Os modelos de compreensão da deficiência atravessam as dinâmicas culturais e produzem implicações que marcam trajetórias e modos de organização social dos espaços e das relações. A deficiência, portanto, pode ser compreendida como produto do entrelace de diversas produções discursivas, que se inter-relacionam com a linguagem, a ideologia e o imaginário social, influenciando condutas e práticas frente a ela. Há diferentes modelos de compreensão da deficiência, e a análise crítica deles e dos efeitos produzidos nas trajetórias das pessoas com deficiência é essencial, do ponto de vista social e político. Ademais, assim como gênero, a deficiência é uma narrativa culturalmente fabricada do corpo e, em função disso, perpassa todos os aspectos da cultura. Ela estrutura instituições, produz subjetividades, práticas culturais, comunidades históricas e posicionamentos políticos (Rosemarie GARLAND-THOMSON, 2002).

O modelo biomédico tem influenciado fortemente as práticas relacionadas à deficiência. O conhecimento científico e os padrões de normalidade compõem os fundamentos desse modelo e constituem a noção do que se entende por deficiência, que se resume às lesões e aos 
impedimentos físicos, sensoriais e intelectuais, entendidos como anormalidades, como o resultado das disfunções em alguma parte do corpo. A partir dessa perspectiva, a pessoa com deficiência começou a ser vista como incapacitada, devendo ser reabilitada para alcançar, o máximo possível, os padrões de normalidade. Tal narrativa, ao penetrar na formação da cultura, cria corpos desviantes e legitima as distribuições não equitativas de recursos, status e poder (Débora DINIZ, 2007; Marivete GESSER; Adriano NUERNBERG; Maria Juraci TONELI, 2012).

Os movimentos sociais de pessoas com deficiência criticaram fortemente o modelo biomédico e a forma como esse influenciava a vida dessas pessoas. Tais movimentos destacavam que, restringindo a deficiência à dimensão biológica, o modelo médico invisibilizava os demais elementos constituintes dela, sendo necessária, portanto, a expansão do diálogo com as áreas humanas e sociais para a compreensão desse fenômeno (Sueli DIAS; Maria OLIVEIRA, 2013). Diante dessa crítica e da necessidade de superar tais visões biologicistas e reducionistas, emergiu o modelo social da deficiência.

A primeira geração de autores do modelo social compreende a deficiência como um processo de opressão e exclusão social. A partir desse modelo, os problemas enfrentados pelas pessoas com deficiência são resultados da opressão social, e não de seus déficits individuais. Isso transfere certa responsabilidade moral para a sociedade. Ou seja, a deficiência é retirada do âmbito individual, e passa-se a enfatizar as barreiras arquitetônicas e atitudinais que limitam a participação das pessoas com deficiência na sociedade, em igualdade de condições com as demais pessoas (DINIZ, 2007). Com base nessa concepção, retiradas as barreiras sociais que obstaculizam a participação das pessoas com deficiência na sociedade, essas poderiam se tornar independentes. Dessa forma, a responsabilidade pelos processos de opressão é vista como da sociedade, e não da pessoa com deficiência; portanto, a sociedade é que deveria "reabilitarse", e não o sujeito (Tom SHAKESPEARE, 2006).

Após 20 anos de hegemonia, a premissa da independência como um valor ético proposta pelos primeiros autores do modelo social da deficiência começou a sofrer alguns questionamentos, que, por sua vez, foram influenciados pela entrada das abordagens pós-modernas e de críticas feministas nos anos 1990 e 2000. A partir disso, definiu-se uma nova concepção do modelo: a segunda geração do modelo social. Essa nova geração de autores, na sua maioria mulheres, sendo algumas delas mães de crianças com deficiência, introduziu novos conceitos que consideravam os papéis de gênero, a dependência, a interdependência, a experiência do cuidado e a dor da lesão como temas centrais na vida da pessoa com deficiência, preocupando-se em discutir não apenas sobre a deficiência, mas o que significa viver em um corpo deficiente ou lesado (DINIZ, 2007).

Os autores da primeira geração do modelo social eram predominantemente homens, intelectuais, em sua maioria portadores de lesão medular, que rejeitavam o modelo médico curativo da deficiência e negavam toda perspectiva caritativa perante ela. Ou seja, princípios como o cuidado, diferenças de gênero ou os benefícios compensatórios para a pessoa com deficiência não eram levados em consideração, pois se entendia que a pessoa com deficiência seria tão produtiva quanto a sem deficiência, caso as barreiras sociais frente à sua deficiência fossem removidas (DINIZ, 2007).

As teóricas feministas, portanto, criticavam a aposta na inclusão feita pelos primeiros estudiosos do modelo, que não questionavam os pressupostos morais da organização social em torno do trabalho e da independência. Criticavam fortemente o argumento do modelo social de que a eliminação de barreiras permitiria que as pessoas com deficiência demonstrassem sua capacidade produtiva, argumentando que era uma ideia insensível à diversidade de experiências da deficiência, visto que nem todas as condições da deficiência permitem viver essa autonomia plena, mesmo com as oportunidades em questão (DINIZ, 2007). Embora haja divergências entre essas duas gerações de teóricos do modelo social, ambas convergem na compreensão de que se deve lutar pelo rompimento das barreiras presentes no contexto social, as quais obstaculizam a participação das pessoas com deficiência em igualdade de condições. Ademais, não é possível compreender a produção do conhecimento relacionada à deficiência como um processo linear, já que vários modelos coexistem e produzem diferentes efeitos no campo científico e político.

O modelo social da deficiência teve muita importância nos avanços das discussões relacionadas à experiência da deficiência e ofereceu contribuições que acabaram por reformular e inspirar alguns marcos legais e políticos relacionados às pessoas com deficiência. Um desses marcos legais foi a Convenção sobre Direitos das Pessoas com Deficiência das Nações Unidas (CDPD). ' Essa Convenção foi construída a partir da ótica de que as próprias pessoas com deficiência são as que sabem o que é melhor para elas e, por isso, devem ser ouvidas em todas as ações que as envolvam. A partir dessa convenção, a deficiência passou a ser cada vez mais considerada como uma questão de direitos humanos.

'Esta Convenção, aprovada em 13 de dezembro de 2006 durante a Assembleia Geral da Organização das Nações Unidas (ONU), em Nova lorque, EUA, foi ratificada pelo Brasil juntamente com o seu Protocolo Facultativo em agosto de 2008, e incorporada no ordenamento jurídico brasileiro sob o status de emenda constitucional por meio do Decreto n. 6.949/2009 (BRASIL, 2009).

2 Revista Estudos Feministas, Florianópolis, 27(1): e48155 DOI: 10.1590/1806-9584-2019v27n148155 
A proposta central da CDPD é instituir o lugar de fala das pessoas com deficiência a partir de sua participação ativa na sociedade, ampliando os direitos básicos conforme os princípios de sua elaboração: a) "nada sobre nós, sem nós", que visa a garantir a participação e o protagonismo da pessoa com deficiência frente às políticas públicas, educacionais e demais questões sociais; b) garantia de não discriminação e não opressão em relação às deficiências e aos impedimentos; c) garantia da inclusão plena em todos os âmbitos sociais; d) aceitação da deficiência como parte da diversidade humana, não como um problema de saúde; e) busca da igualdade de oportunidades em sentidos ampliados, no mercado de trabalho, na educação e nas mais diversas esferas; f) garantia da acessibilidade, que visa a assegurar acessos e diminuição das limitações sociais das pessoas com deficiência; g) equiparação de gênero, de modo que não haja distinção entre homens e mulheres com deficiência sob nenhum aspecto social, e, por fim; h) consideração e transformação na condução da educação das crianças com deficiência, a fim de transpor as limitações impostas pela exclusão e propor diferentes formas de ensino (Amita DHANDA, 2008).

A CDPD tem como propósito proteger e assegurar as condições de igualdade dos direitos humanos e liberdades fundamentais para todas as pessoas com deficiência e, por isso, torna-se um forte instrumento de ação política na medida em que agrega, ao seu arcabouço jurídico, um instrumento de pesquisa, conhecimento e ação. O Preâmbulo da CDPD reconhece que a deficiência é um conceito em evolução, mas realça também que a deficiência resulta da interação entre pessoas com deficiência e barreiras comportamentais e ambientais que impedem sua participação plena e eficaz na sociedade de forma igualitária (BRASIL, 2009). Dessa forma, a ampliação da participação social das pessoas com deficiência pode ocorrer pela minimização das barreiras que as afetam na vida diária. Um dos elementos apresentados pelas teóricas vinculadas aos Estudos Feministas da Deficiência integrado à CDPD foi o referente à interseccionalidade entre gênero e deficiência. Esse será objeto do próximo tópico.

\section{A interseccionalidade entre gênero e deficiência}

Como vimos, a união dos campos teóricos de gênero e deficiência contribuiu para que uma nova forma de pensar sobre a deficiência fosse considerada, enriquecendo as formas de se compreender a justiça social, a constituição do sujeito, os saberes subjugados e as ações coletivas (GARLAND-THOMSON, 2002).

Além disso, a segunda geração do modelo social da deficiência começou a aprofundar a compreensão da deficiência como constituída na interseccionalidade com marcadores sociais tais como geração, gênero, etnia, classe social, religião e região. Sendo assim, objetivaram questionar as categorias identitárias, ampliando as noções de identidade para garantir a viabilização de políticas públicas que considerem as diversas formas de ser e estar no mundo.

Assim como as teorias feministas procuraram expandir o olhar sobre a categoria de gênero e as produções culturais a ela relacionadas e, em função disso, contribuíram para desestigmatizar a posição da mulher na sociedade, os estudos sobre deficiência, por elas influenciados, também seguiram na mesma direção. As teorias feministas possibilitam, de acordo com Garland-Thomson (2002), o questionamento e a investigação de como a cultura impregna significados nas particularidades do corpo e quais as consequências desses significados. Ou seja, como as representações de gênero, raça, etnia, habilidades, sexualidade e classe interseccionalmente constroem, inferem e contradizem umas às outras, produzindo identidades e movimentos de opressão social.

As teóricas feministas da deficiência problematizam cuidadosamente uma grande gama de materiais e práticas que envolvem o corpo, e isso as distingue de outras teorias críticas. Baseiamse nas premissas da teoria crítica que concebe que: as representações estruturam realidades; as margens definem o centro; gênero e deficiência são formas de significar relações de poder; a identidade humana é múltipla e instável, e toda análise e avaliação têm implicações políticas (GARLAND-THOMSON, 2002). Assim como raça e gênero, a deficiência está em todos os lugares, desde que nós saibamos como olhar para eles. Esta crítica intelectual proposta por GarlandThomson (2002) tem um potencial político, pois destaca que, da mesma forma que gênero, raça, sexualidade e classe, para entender como a deficiência opera é necessário entender todos esses atravessamentos existentes e mutáveis nos sujeitos.

Nesse sentido, Kimberlé Crenshaw (2002) propõe que a interseccionalidade é mais do que unir duas contingências sociais. Aponta que esses atravessamentos são pontos nodais para a materialização e subjetivação das condições ditadas, promovendo espaços de marginalização e não aceitação da diversidade como forma de vida histórica e social. Ao introduzir essa questão central aos estudos feministas, a autora abre condições para que se discutam intersecções para além da raça, e que possibilitam entender de fato o processo de existência como produzido cultural e historicamente (Kimberlé CRENSHAW, 2002).

Contudo, apesar de o gênero ter sido incorporado pelos estudos sobre a deficiência como uma categoria de análise, a deficiência ainda não foi incorporada como categoria nos estudos feministas. Garland-Thomson (2002) critica que temas que são intrínsecos à deficiência - como 
tecnologia reprodutiva, o lugar das diferenças corporais, as particularidades da opressão, a ética e o cuidado, e a construção de sujeito - são estudados no feminismo isoladamente, sem que se estabeleçam relações com a experiência da deficiência. Para a autora, essa resistência de unificação das categorias gênero e deficiência se deve ao fato de que ainda há uma noção reducionista de identidade em alguns estudos feministas. ${ }^{2}$ Nesse sentido, a autora propõe a integração da categoria deficiência nos estudos feministas e cria um novo marco teórico: os feminist disability studies, ${ }^{3}$ traduzido para o português como estudos feministas da deficiência (GARLAND-THOMSON, 2002).

A teoria feminista da deficiência, portanto, vai integrar os estudos feministas àqueles sobre deficiência, num contexto político e de movimento de direitos humanos para articular suas contribuições, frente à explícita relação que o feminismo assume entre o trabalho intelectual e o compromisso para criar uma sociedade mais justa, equitativa e integrada. Para Garland-Thomson, essa pode ser considerada como uma área acadêmica de investigação e pode ser uma das categorias de análise dentro dessa diversidade, ampliando as noções de diversidade e integrando profundamente a academia e o contexto coletivo (GARLAND-THOMSON, 2002).

De forma complementar, os estudos feministas da deficiência também contribuem para o questionamento da constituição dos sujeitos a partir de conceitos normativos. Os estudos de Judith Butler (2004) e Eva Kittay (2015) mostram como nossas tentativas discursivas emergem para humanizar certas vidas e silenciar outras, e como isso acaba por perpetuar a violência normativa que privilegia algumas vidas em detrimento de outras.

A partir dos estudos feministas da deficiência, os estudos contemporâneos sobre deficiência começaram a ocupar um espaço multidisciplinar, sendo consideradas as perspectivas da medicina, da antropologia, da sociologia e da psicologia. A variada natureza da teoria crítica dos estudos sobre deficiência levou Lennard Davis (2006) a definir o campo contemporâneo como dismodernist, em que a deficiência une outras intersecções como ponto de reflexão. Para Dan Goodley (2013), os estudos críticos da deficiência começam, mas nunca terminam com ela: a deficiência é o espaço a partir do qual pensar por meio de uma série de questões políticas, teóricas e práticas é relevante para todos.

No Brasil, a interface do feminismo com os Estudos sobre Deficiência tem sido realizada, sobretudo, pela Anis - Instituto de Bioética, Direitos Humanos e Gênero. ${ }^{4}$ Tal instituição desenvolve ações de capacitação e produção de conhecimento em torno das questões de bioética e deficiência, em parceria com o grupo de pesquisa Ética, Saúde e Desigualdade, da Universidade de Brasília (UnB). Além disso, muitos pesquisadores vinculados ao Núcleo de Estudos sobre Deficiência ${ }^{5}$ da UFSC têm estudado a relação entre gênero e deficiência com base em uma perspectiva interseccional e política.

Com vistas a ampliar e atualizar os estudos já publicados no Brasil, o presente artigo vislumbra apresentar o resultado de uma revisão integrativa de literatura atualizada acerca da temática gênero e deficiência a nível internacional, no intuito de aproximar os avanços do campo dos estudos feministas da deficiência que já vêm sendo realizados internacionalmente à produção científica nacional, nas produções de autoras e autores vinculados à segunda geração desse modelo.

\section{Percurso metodológico}

O campo dos estudos da deficiência, embora bastante extenso no cenário internacional, é relativamente novo no Brasil. Anahi Mello e Adriano Nuernberg (2012) produziram um trabalho similar ao aqui proposto, que objetivou apresentar as intersecções entre gênero e deficiência discutidas até ao ano de 2012. Os autores apresentaram os temas resultantes dessa intersecção, à luz da segunda geração do modelo social da deficiência, baseada já nos estudos feministas, em sua maioria internacionais. Nesse trabalho, Mello e Nuernberg (2012) abordaram alguns eixos de discussão identificados por: a) masculinidades, feminilidades e deficiência; b) deficiência, cuidado e feminismo; c) corporalidade e deficiência; d) deficiência, sexualidade e direitos reprodutivos; e) violência de gênero e deficiência. Visando discutir esses eixos, os autores evidenciaram a importância da intersecção gênero e deficiência para o campo dos estudos sobre deficiência, bem como para os estudos de gênero.

\footnotetext{
${ }^{2}$ Entende-se, neste trabalho, que o movimento feminista se estende em diversas vertentes que se posicionam diferentemente em relação a conceitos e disputa de direitos.

${ }^{3}$ Feminist Disability Studies é um campo de produção do conhecimento que questiona o discurso médico que caracteriza a deficiência como uma falha, uma patologia, ou um déficit a ser corrigido ou eliminado e situa essa categoria como social e política e propõe a análise da experiência da deficiência no contexto de direitos e exclusões. Ademais, esse marco teórico: a) entende a deficiência como um sistema de exclusão que estigmatiza as diferenças humanas; b) visibiliza comunidades e identidades que os corpos que consideramos deficientes produziram; c) revela atitudes e práticas discriminatórias dirigidas a esses corpos; d) defende a deficiência como uma categoria social de análise; e) enquadra a deficiência como um efeito das relações de poder (GARLAND-THOMSON, 2005).

${ }^{4} \mathrm{O}$ site http://www.anis.org.br apresenta os objetivos e os trabalhos dessa organização.

${ }_{5} \mathrm{O}$ site http://nedef.paginas.ufsc.br/ apresenta os objetivos e os trabalhos desse núcleo.
} 
Tomando por base o texto supracitado, buscou-se uma atualização do assunto que abrangesse o último quinquênio, contemplando produções realizadas nos anos de 2010 a 2015. Este texto, portanto, é decorrente de uma pesquisa de revisão integrativa de literatura e tem o intuito de fazer uma atualização da produção do conhecimento utilizando a intersecção gênero e deficiência como o marcador temático.

Como descritor de busca, foi utilizado o termo feminist disability studies. A escolha desse descritor justifica-se em função da sua utilização na literatura científica internacional para se referir aos estudos feministas da deficiência. A revisão foi realizada no portal de periódicos CAPES, que foi escolhido como base de dados por ser uma biblioteca virtual que reúne e disponibiliza uma ampla produção científica internacional.

Dos 49 artigos encontrados, 24 foram utilizados por cumprir o critério de inclusão definido: investigar especificamente assuntos relacionados à perspectiva dos feminist disability studies. Como instrumento de organização dos dados coletados, foi utilizada uma ficha de catalogação. Nessa, foram listados os autores, os títulos, o ano de publicação, os participantes e os principais resultados.

Ao longo de todo o processo da presente revisão, a proposta geral foi a de verificar correlações que buscassem promover algumas compreensões atuais sobre a intersecção gênero e deficiência, por meio das produções dos feminist disability studies, objetivando produzir reflexões para o campo dos estudos sobre deficiência e para os estudos feministas na produção brasileira e apresentando seus principais achados. Vale ressaltar que o presente artigo não pretende esgotar as considerações produzidas pelos textos originais, permitindo a compreensão geral das temáticas, mas sugerindo sempre a leitura integral dos trabalhos referenciados.

\section{Eixos temáticos}

No decorrer da revisão, visando facilitar as correlações e reflexões, identificaram-se quatro eixos transversais, que abordam especificamente assuntos discutidos pelos estudos feministas da deficiência: as lacunas dos estudos feministas com relação à deficiência; cuidado e interdependência; sexualidade, e novas possibilidades de intersecção.

É importante destacar a publicação Proliferating Cripistemologies: A virtual Roundtable, de Robert McRuer e Merri Johnson (2014), que reuniu, em uma mesa-redonda virtual, teóricas queers, trans, feministas, da deficiência e negras em torno da questão de como pode a epistemologia crip operar. Nessa mesa, debateu-se sobre em que aspectos se aproximam e se distanciam as teorias queer, feministas e da deficiência; os impactos dos ativismos; as capturas pelo capitalismo neoliberal que domestica corpos; as torções e desconstruções nos corpos e identidades compulsórias; dentre outros temas. Acreditamos que esse debate merece ser revisitado. Na continuidade deste texto, apresentaremos alguns dos achados que remetem (e sustentam) 0 que foi problematizado nesse artigo.

\section{Lacunas dos estudos feministas com relação à deficiência}

Algumas produções vêm interpondo a necessidade e a relevância da interseccionalidade entre gênero e deficiência. Desse modo, o eixo a seguir elenca as principais ideias e aproximações desses artigos no que tange à importância dos estudos interseccionais.

Argumentando que o conceito de sororidade ${ }^{6}$ tem sido convincente para pensar sobre os elos entre as mulheres na política feminista, mas que muitas vezes instala uma igualdade ilusória entre mulheres de diferentes raças, sexualidades e corpos, Helen Davies (2014) apresenta questionamentos sobre os perigos em manter essa irmandade nos estudos sobre a deficiência. A autora afirma que, por excluírem a deficiência como uma categoria transversal de análise, os estudos feministas deixam de considerar aspectos importantes no processo de constituição da identidade e da subjetivação. Davies (2014) também destaca que, ao se utilizar de metáforas dos corpos - como monstros, grotescos e cyborgs - para sugerir um potencial transgressivo na política feminista, deixa-se de perceber que tais termos se referem, muitas vezes, à realidade dos corpos das pessoas com deficiência.

Além disso, Ashley Taylor (2015, p. 194) afirma que questões centrais pautadas pelo feminismo como as tecnologias reprodutivas e o aborto têm diferentes implicações para mulheres com deficiência, cuja "própria existência é posta em questionamento em função da 'nova eugenia'", enfatizando a necessidade dessa intersecção para fomentar as discussões em todas as esferas.

Therí Pickens (2015), por sua vez, aponta para a importância das análises de Judith Butler, em relação aos conceitos de precariedade, processos de inteligibilidade e enquadramentos que são dados às vidas marginalizadas, argumentando serem perfeitamente compatíveis com os estudos feministas da deficiência, evidenciando ainda que esses conceitos são fundamentais nessa discussão.

\footnotetext{
${ }^{6}$ Sororidade é denominado por Suely Costa (2004) como um misto de sentimento e utopia que tem presidido os
} movimentos feministas, o qual é baseado em uma suposta identidade biológica entre as mulheres. 
Na produção de Kim Hall (2015), surge um convite a refletir sobre a posição da deficiência e dos estudos sobre deficiência no feminismo e na filosofia feminista. Um dos objetivos dos estudos feministas da deficiência tem sido, segundo a autora, o de tornar visível a diversidade da vida com deficiência, bem como de criticar as suposições sobre a deficiência que dizem respeito ao feminismo (HALL, 2015). Em resumo, ela compreende que a deficiência desempenha um papel muitas vezes não reconhecido e não autorizado nas análises contemporâneas feministas. Salienta, ainda, que análises com essas intersecções são vitais para a filosofia feminista e a própria filosofia geral. Hall evidencia a necessidade de se produzir um feminismo sem fronteiras, no qual o destaque atribuído às singularidades possibilita a transcendência dos limites teóricos que potencializam uma ruptura entre as perspectivas feministas.

\section{O culdado e a Interdependêncla}

A questão do cuidado aparece de forma recorrente nos artigos. Uma das principais questões evidenciadas é a problematização, proposta por Garland-Thomson, que diz respeito à qualidade do cuidado como argumento crítico frente à eugenia liberal, em que a escolha para melhorar ou eliminar variações humanas por meio de tecnologias reprodutivas e genéticas é entendida como uma questão de preferência individual e ação do consumidor, em vez de uma política de saúde pública do Estado. Nesse sentido, explicita que a presença ou ausência de uma deficiência durante a gestação não prediz a qualidade de vida futura dos sujeitos. O cuidado e a interdependência são vistos pela autora como essenciais para garantir a qualidade de vida, evidenciando que a autonomia está atrelada a necessidades singulares e que o cuidado é visto como possibilidade de melhor viver, e não como submissão ou fardo. Segundo Garland-Thomson (2015), devemos incluir e criar condições de possibilidades para as pessoas com deficiência, ao invés de eliminá-las antes mesmo de Ihes dar a chance de viver.

O cuidado também emerge em associação com a vulnerabilidade das pessoas com deficiência que precisam de cuidadores. Anita Silver (2015) problematiza as relações de cuidado a partir de um caso de agressão do cuidador para com o sujeito do cuidado, propondo, através das noções sobre envelhecimento e deficiência, a reformulação de uma justiça pautada na dependência. Em seu artigo, o autor discorre politicamente sobre o tema do cuidado, discutindo as questões jurídicas dessa prática e a necessidade do diagnóstico para receber o direito ao cuidado. Além disso, atenta para a complexidade da relação e dos sentimentos entre cuidadores e cuidados. Para Silver (2015), se malvistas e maltratadas pelos outros, as pessoas com deficiência têm prejuízos à sua autoestima, o que pode debilitar sua capacidade de protestar de forma eficaz, respondendo por sua própria autonomia.

Tanto Garland-Thomson quanto Silver, ao abordarem a temática do cuidado, apoiam-se no referencial de Eva Kittay (GARLAND-THOMSON, 2015; SILVER, 2015) sobre a ética do cuidado baseada nas concepções de interdependência e justiça social, evidenciando a importância da autora nas produções frente a essa temática.

Stacy Simplican (2015), por sua vez, problematiza as relações de vulnerabilidade do cuidado com enfoque no cuidador, afirmando que, em casos complexos de dependência, as pessoas que dependem de cuidados podem encontrar maneiras de exercer o poder frente à vulnerabilidade do cuidador. Nesse sentido, oferece importantes reflexões acerca da 'idealização da deficiência', pela qual os sujeitos com deficiência são vistos como incapazes de se tornarem agressivos. Simplican (2015) argumenta que tal idealização pode ser compreensível quando o trabalho frente à deficiência é situado dentro de uma disciplina que rotineiramente desumaniza essas pessoas, em que qualquer admissão de traços negativos aparentemente fornece 'pontos para o adversário'. Para ela, as noções idealizadas das pessoas com deficiência excluem sujeitos não conformes e mascaram experiências alternativas de cuidado. A autora expande as noções sobre dependência, introduzindo o termo "dependência complexa" para conceituar as situações em que os cuidadores de pessoas com deficiência podem vivenciar condições de vulnerabilidade.

Além disso, Simplican faz reflexões sensíveis sobre a relação entre cuidador e cuidado no que se refere à importância da interpretação das necessidades dos outros (em caso de deficiências severas) e sobre o desgaste emocional dos cuidadores que se tornam os únicos responsáveis pelos cuidados complexos, visto que o Estado não se responsabiliza por isso. Com base no pensamento de Kittay (1999 apud SIMPLICAN, 2015), a interdependência não é uma questão de voluntarismo e aponta para a importância de uma estrutura social que possa atender as necessidades de cuidados para com as pessoas que deles dependem e para os trabalhadores que atuam como cuidadores.

Frente a essas situações, Simplican apoia-se em Joan Tronto (2010 apud SIMPLICAN, 2015) para reivindicar um modelo de cuidado que seja repensado a partir da complexidade e da singularidade que envolvem essa relação, e que aponte como lidar e responder aos conflitos que emergem dessa relação sem reforçar a invisibilidade ou vulnerabilidade dos(as) cuidadores(as).

6 Revista Estudos Feministas, Florianópolis, 27(1): e48155

DOI: 10.1590/1806-9584-2019v27n148155 
Nesse sentido, afirma que a teoria feminista da deficiência deve responder também às violências que ocorrem contra os(as) cuidadores(as) e questionar como as comunidades podem proteger e tornar suas vidas menos precárias. Para o cuidado efetivo, devemos compreender possíveis riscos, que envolvam diversas formas de violência e abuso, tornando nossos ideais e instituições aptos para lidarem com a dependência complexa (SIMPLICAN, 2015).

Endossando esse eixo transversal referente ao cuidado e às questões de dependência, o artigo elaborado por Laura Davy (2015) propõe que a teoria feminista da deficiência redesenhe conceitos filosóficos fundamentais, visando à criação de oportunidades e desconstruindo barreiras para a inclusão das pessoas com deficiência. Nessa vertente, a autora também faz uma severa crítica ao conceito de autonomia, dando relevância e ampliando a discussão sobre a interdependência como forma de experiência da pessoa com deficiência (DAVY, 2015). Nesse sentido, corrobora com o estudo supracitado de Kittay (1999 apud DAVY, 2015), que propõe que as formas de vivenciar a deficiência passam pelas relações de interdependência que, se conduzidas pela ótica do cuidado, permitem a máxima vivência da autonomia, promovendo a lógica da equidade.

Laura Back (2015) também faz menção às relações de cuidado e interdependência, despertando a reflexão sobre a dependência ser direcionada unicamente às relações de parentesco de primeiro grau, argumentando que essa relação de interdependência está, ou deve estar, entrelaçada à esfera política estatal e pública. Reforça a necessidade de apoio coletivo e social de forma ampla aos cuidadores e aos sujeitos do cuidado (BACK, 2015). Para tal argumentação, a autora também se apoia nas premissas sobre a lógica e a ética do cuidado cunhadas por Kittay (1999 apud BACK, 2015).

O trabalho de Margaret Price (2015) traça aproximações entre a teoria queer e as políticas crip, argumentando que são perspectivas que, embora distintas, mostram pontos em comum, como a perspectiva da desconstrução das identidades fixas, da contingência e da flexibilidade, de forma a mesclar academia e ativismo, assim como permitir a coalizão entre as várias categorias da deficiência. A autora utiliza o neologismo "corpo mente" como tentativa de superar a cisão entre as duas instâncias, argumentando sua constituição sociopolítica e material em meio a contextos estruturais (atravessados por relações de poder e violência) e singulares (experiências dos sujeitos) (PRICE, 2015). A partir dessas considerações, Price problematiza a relação entre desejo e dor, corpos desejantes e desejáveis no contexto das deficiências, mantendo uma perspectiva interseccional. O acolhimento da dor do outro e a gentileza no/do cuidado em suas necessidades singulares são fundamentais em contextos como esses (PRICE, 2015).

Em resumo, é possível concluir que a questão do cuidado cunhada por Kittay (2011) e ampliada nos estudos feministas vinculados à segunda geração do modelo social da deficiência, vem como polo de desconstrução da busca por independência e igualdade tão difundida como bandeira de luta das pessoas com deficiência, a partir da primeira geração. Com relação ao cuidado, os estudos feministas da deficiência, através da premissa da interdependência, evidenciam a dependência complexa e suas implicações na relação cuidador-cuidado, por meio do viés político, denunciando o quanto o princípio de interdependência exige uma ampla gama de preocupações políticas.

\section{Sexualidade}

O tema da sexualidade é abordado nos estudos feministas da deficiência com um foco voltado à garantia dos direitos sexuais e reprodutivos às pessoas com deficiência, até então marginalizadas por concepções incapacitantes.

Tracy De Boer (2015) problematiza as atitudes sociais acerca da imagem corporal, do sexo e da sexualidade que dificultam a expressão sexual e as oportunidades sexuais para pessoas com deficiência. Nesse sentido, a autora argumenta sobre a escolha das pessoas com deficiência pelo sexo comercial dialogando com a ideia da dominação masculina que permeia tal assunto. A visão da escolha sexual atravessada pela ideia da dominação masculina, segundo a autora, implica que os homens com deficiência construam a sua sexualidade (e masculinidade), da mesma forma como fazem os homens sem deficiência. Apesar de reconhecer os problemas pertinentes às questões de gênero e opressão, a autora afirma que tal escolha pode desempenhar um papel importante para a afirmação do sujeito como um ser sexual, bem como para promover a sua inclusão sexual, visto que essa busca envolve a procura por conexão, intimidade e prazer (DE BOER, 2015). Diante de tal cenário, De Boer (2015) afirma que a reforma dos 'sentimentos públicos', entendidos pelo autor como preconceitos, mitos e medos em torno da vivência plena da sexualidade das pessoas com deficiência, é vista como um dos critérios que precisam ser desconstruídos para a inclusão sexual e afetiva.

Outro assunto abordado dentro dessa categoria diz respeito à maternidade de mulheres com deficiência. Frente à crença de que mulheres com deficiência não são capazes de fornecer cuidados maternos, os estudos feministas da deficiência, dentro do trabalho de Harold Braswell 
(2015), apontam para a necessidade de questionar as concepções normativas de cuidado materno para reconhecer as diversas e alternativas estruturas de parentesco capazes de auxiliar nesse cuidado, salientando a interdependência como uma das alternativas da equidade de possibilidades. Para sustentar essa argumentação, Braswell se utiliza dos estudos de Butler (2003 apud BRASWELL, 2015) sobre parentesco para repensar os estudos maternos de Donald Winnicot, numa concepção crítica ao essencialismo e às formas de cuidado privado.

Outro tema emergente nesse eixo refere-se à escolha reprodutiva de mulheres que, nos testes pré-natais, identificam 'anomalias' nos fetos. Alison Piepmeier (2015) objetivou compreender o processo de decisão reprodutiva dessas mulheres evidenciando que, apesar de todas se identificarem como mães, sentiam dificuldade na decisão entre manter a gestação ou realizar um aborto. Contudo, Piepmeier (2015) constatou que a maioria das mulheres optava pela continuidade da gestação. Os insights desse trabalho permitem reflexões que incorporam os estudos feministas da deficiência tanto no que tange à decisão pela gestação, o direito ao aborto, quanto na compreensão da precariedade de uma vida que difere dos padrões normativos a ponto de não poder tornar-se uma vida.

Além de Piepmeier (2015), Catherine Mills (2015) também ofereceu importantes reflexões sobre a escolha reprodutiva frente às determinações feitas sobre fetos com anomalias morfológicas. Utilizando-se das reflexões realizadas pelos estudos feministas sobre a seleção de sexo na gestação, a autora afirma que um feto com deficiência pode ser considerado uma gestação normal se questionarmos os modelos binários e normativos que atravessam o discurso social. Conclui que o reconhecimento dessa indecisão pode ser necessário para a avaliação responsável da ética da interrupção seletiva (MILLS, 2015).

Dentro desse mesmo eixo temático, emergiram artigos que apontam as contribuições das teorias crip e queer ${ }^{7}$ para os estudos da deficiência. Embora reconhecendo a intersecção profícua entre os estudos queer e da deficiência, Merri Johnson (2015) argumenta que a teoria queer mostra relutância em abordar a deficiência de forma significativa. Para além das classificações clássicas ou das terminologias utilizadas pelas teóricas queer, Johnson (2015), a partir da crítica a outras pensadoras e de sua própria experiência, problematiza a invisibilidade de determinadas condições de deficiência, em especial as desordens mentais, para a teoria queer. Estabelece uma coalizão crítica entre a teoria feminista crip e a teoria queer-of-color para promover uma política materialista e prática de sorte a reconhecer subjetividades minoritárias ao invés de explorá-las apenas em sua ressonância metafórica (JOHNSON, 2015). A autora conclui que a análise feminista crip deve, de uma vez por todas, reconhecer os prazeres da 'falha'- incorporada nas escolhas de se colocar à parte dos marcadores normativos de gênero, sexualidade, reprocentricity ${ }^{8}$ e afiliação. Nesse sentido, Johnson (2015) convida para que um 'romance melhor' emirja entre as teorias crip e queer, principalmente no que diz respeito à análise das diferenças entre as duas pelos estudos feministas da deficiência.

Outro artigo analisado foi o de Joshua St. Pierre (2015), o qual, a partir do que o autor chama de uma fenomenologia feminista, queer e crip, problematiza o lugar do corpo gago e sua temporalidade e (im)possibilidade de reconhecimento ao perturbar a coreografia de comunicação normalizada com base na hegemonia 'tempo do homem hétero'. O autor argumenta sobre a existência de uma linearidade dirigida para o futuro, captada a partir do fluxo de tempo corporal e o quanto isso atrapalha o desempenho da performance de homens com deficiência sobre suas masculinidades, por serem consideradas interrompidas ou diminuídas. Para o autor, o 'tempo relógio' disciplina os sujeitos a se moverem em movimentos padronizados e eficientes. Por 'perturbar' essa coreografia do tempo, a pessoa com deficiência não é reconhecida em sua própria voz (ST. PIERRE, 2015). Frente a isso, St. Pierre (2015) afirma que os sujeitos com deficiência são capazes de transformar o espaço comunicativo estabelecido, não permitindo o controle de tempo imposto, mas acentuando a 'co-constituição' do ser. A proposta do autor em desconstruir o 'tempo do homem hétero' é uma abertura existencial: um convite para orientar dentro de um presente não produtivo, bem como um chamado para os sujeitos assumirem a responsabilidade por seu papel na criação de um horizonte comum, visando à posterior liberação da voz da pessoa com deficiência, isto é, dentro de um futuro dos estudos crip (ST. PIERRE, 2015).

Supondo essa vivência da diversidade, os eixos binários de capacidade/deficiênciacisgênero/transgênero são apontados por Alexandre Baril (2015) a fim de questionar as fronteiras entre uma experiência transgênero e uma transabled (modificação voluntária do corpo para que tenha alguma deficiência). O autor identifica dois aspectos que impedem a conceituação e colocação das duas categorias no mesmo segmento: primeiro, porque os estudos trans não assumem a possibilidade de uma identidade trans com deficiência; segundo, porque os estudos

${ }^{7}$ Movimentações teórico-políticas que passam a fazer parte, a se tornar mais visíveis, conforme determinados sujeitos buscam se posicionar de específicas maneiras (como mulheres, gays/lésbicas, deficientes) e, consequentemente, acabam por criar os próprios espaços para que esses posicionamentos façam sentido (feminismos, estudos gays/ lésbicos - queer, disability studies/theory, crip theory).

${ }^{8} \mathrm{O}$ termo reprocentricity pode ser caracterizado como uma norma relacionada à reprodução.

8 Revista Estudos Feministas, Florianópolis, 27(1): e48155

DOI: 10.1590/1806-9584-2019v27n148155 
sobre deficiência assumem uma identidade cisnormativa de pessoas com deficiência. $O$ autor critica, então, tais lógicas de produção nesses dois campos, enfatizando as dificuldades em reconhecer as intersecções entre esses fenômenos, uma vez que eles se dão pela atribuição normativa entre sexo/gênero e cisnormatividade e, simultaneamente, por uma interpretação normativa de não deficiência. Ao tornar complexas as relações entre os dois campos a partir da desconstrução nas normatividades naturalizadas, busca aproximar e intensificar o diálogo entre os estudos e os movimentos sociais trans e os da deficiência (BARIL, 2015).

Margrit Shildrick, partindo da pergunta de Donna Haraway (1990 apud SHILDRICK, 2015) "por que nossos corpos deveriam terminar na pele?" -, explora os fundamentos dos sentidos para reavaliar as múltiplas e variantes formas de existência. Apoia-se em Gilles Deleuze e Jacques Derrida e suas concepções sobre o posicionamento de celebração da diferença e 'transcorporeality' como as próprias condições de vida, produzindo discussões sobre as diversas formas dos corpos no mundo, incluindo a deficiência e seus arredores como expressões diversas e transcorpóreas (SHILDRICK, 2015).

Foi encontrado, também, um artigo que propõe a unificação entre os estudos sobre a deficiência e os estudos $\mathrm{LGBT}^{9}$ a partir de uma perspectiva pós-racial e pós-espacial, construindo e produzindo engajamento crítico com os discursos de visibilidade e seus acompanhantes de ideologias pós-racial e pós-espaciais, corroborando para a criação de um novo panorama teórico no feminismo. Carly Thomsen (2015), através da análise das falas de ativistas com deficiência e LGBT, ilustra como a busca por ambas as categorias pela visibilidade dos discursos produz como efeito a invisibilidade de determinados corpos materiais interseccionados pelos marcadores de raça e espaço geográfico. A autora propõe a criação de uma teoria transformadora feminista da deficiência e prática, a qual deve ter como premissa o rompimento com entendimentos fixos acerca das identidades e com a hierarquização das opressões. Essa teoria deve ser baseada na convicção de que modos alternativos de operar no mundo (incluindo aqueles para além do fora) são realmente possíveis (THOMSEN, 2015).

A sexualidade é sempre uma temática delicada, e não se faz diferente nos estudos sobre deficiência; é uma tarefa árdua vislumbrar a desconstrução dos preconceitos em torno dessa temática. As questões pertinentes aos estudos sobre sexualidade, sexo e demais questões que permeiam essa intersecção são percebidas nos estudos acima citados como fonte de preconceitos, tabus e mitos. Desse modo, torna-se fundamental, no processo de garantia de direitos sexuais e reprodutivos, a desconstrução de narrativas normalizadoras.

\section{Novas intersecções}

Nesse eixo, são evidenciadas correlações inovadoras dentro dos estudos feministas da deficiência. Anna Mollow (2015) associa os estudos da obesidade (fatstudies) aos estudos da deficiência e argumenta sobre a importância das contribuições dos estudos feministas da deficiência para pensarmos na obesidade e vice-versa, visto que a obesidade atravessa 0 imaginário cultural assim como a deficiência, criando barreiras sociais de forma similar. Para a autora, as mesmas formas que existem para reabilitar os sujeitos com deficiência para se adequarem à sociedade são vistas na relação com a obesidade, atravessadas pelo discurso da saúde e da necessidade de dietas e processos cirúrgicos para que essas pessoas possam ser consideradas como normativas dentro do contexto, o que gera sofrimento e rejeição da diversidade humana (MOLLOW, 2015). Com base nas reflexões da autora, podemos dizer que o modelo médico da deficiência produz efeitos semelhantes junto à população obesa, considerando-os 'defeituosos' e recomendando sua reabilitação para que se enquadrem nos padrões normativos.

Outro estudo, de autoria de Diane Herndl (2013), também de caráter peculiar, remete ao diagnóstico $\mathrm{BRCA}^{10}$ como uma forma de identidade, e fala da influência do diagnóstico como uma estrutura narrativa que pode enquadrar a pessoa numa história de doença que ainda não é. Quando um sujeito descobre ser BRCA positivo, o câncer não é apenas um potencial, mas se torna uma parte da identidade. A autora utiliza histórias sobre esse teste para esclarecer uma definição de pós-humano como existente no cruzamento de corpos, tecnologias e narrativas. Nesse sentido, o termo pós-humano surge como forma de tecnologização dos corpos. Ao utilizar as teorias feministas da deficiência para enquadrar essas histórias, emerge a possibilidade de compreender as transformações para esses sujeitos, designados como seres de futuro, na lógica do pós-humano (HERNDL, 2013).

Ashley Taylor (2015) propõe a associação entre raça e deficiência intelectual, evidenciando uma relação existente entre as duas categorias, visto que pessoas negras são, muitas vezes, consideradas não intelectualizadas e, em função disso, silenciadas nos discursos acadêmicos. Frente a isso, Taylor (2015) afirma que, quando o discurso acadêmico não problematiza a questão

\footnotetext{
${ }^{9}$ Termo utilizado pela autora no artigo original.

${ }^{10} B R C A$ (breast cancer) é um gene humano que pertence à classe de genes conhecida como genes supressores de tumor, que regula o ciclo celular e previne a proliferação descontrolada.
} 
social da deficiência intelectual associada à raça, ele reproduz o discurso patologizante que conforma as barreiras de opressão e marginalização. A autora chama isso de 'racialização da deficiência intelectual'. Segundo ela, a academia deve ter cuidado ao privilegiar as 'mentes capazes' e sua associação com a valorização da identidade racial para se proteger contra fáceis deslizamentos no discurso da patologia (TAYLOR, 2015).

Nesses novos atravessamentos que emergiram, entende-se como importante olhar pelo viés do cuidado e da interdependência sobre essas sutis margens das margens. Desse modo, será possível visibilizar todas as expressões da diversidade humana.

Numa elaboração sobre inclusão social, Amber Knight (2015) examina, em sua produção, as condições necessárias e significativas, dentro de uma democracia deliberativa, proposta como um caminho para a efetivação da inclusão. A análise conclui que uma verdadeira democracia inclusiva e multicultural requer a redistribuição da riqueza e um modelo mais amplo de deliberação política, que reconheça os modos não convencionais (mesmo não-verbais) de comunicação, por meio de práticas de tradução (KNIGHT, 2015). A autora contribui afirmando que escutar os próprios sujeitos com deficiência é fundamental para a construção de políticas públicas adequadas para sua realidade social.

Por fim, essas questões que entrelaçam inclusão em diversos contextos vão possibilitar novas compreensões e ampliar temáticas já discutidas no campo interseccional de estudos sobre deficiência e gênero. Em síntese, essas produções têm o intuito de problematizar a exclusão decorrente das apropriações sociais da normatividade e os enquadramentos por elas designados.

\section{Considerações finais}

O campo dos estudos feministas da deficiência surge com a finalidade de se romper a cisão histórica entre gênero e deficiência. Essa esteve presente até então tanto nos estudos de gênero - que não incluíam a deficiência como categoria de análise - como nos estudos sobre deficiência - cujos autores da primeira geração desse modelo não consideravam as questões de gênero, raça, geração e demais marcadores sociais das diferenças como elementos constituintes da experiência da deficiência.

Partindo do pressuposto de que diferentes modelos de compreensão da deficiência têm efeitos sociais e políticos, uma importante contribuição dos estudos feministas da deficiência foi a de mostrar que o enquadramento da deficiência baseado no modelo biomédico produz opressão e vulnerabilidade, tornando precárias as condições de existência das pessoas com deficiência. Isso porque esse modelo, ao estabelecer um padrão normativo de corpo, torna ininteligíveis as corporeidades que escapam desse modelo. Além disso, o modelo biomédico, ao estabelecer um padrão de resposta sexual normal, corrobora o processo de transformação das pessoas com deficiência como assexuadas, limitando os direitos sexuais e reprodutivos desse grupo social.

Como visto ao longo do texto, o campo dos estudos feministas da deficiência oferece importantes contribuições para as ciências sociais e humanas, bem como para a produção de políticas públicas que tenham o potencial de considerar/incluir todas as formas de ser/estar no mundo. Uma dessas contribuições é a de ampliar as noções de identidade para garantir a viabilização de políticas públicas que considerem as diversas formas de existência. Outra contribuição se refere à preocupação em tornar as vidas não normativas mais inteligíveis, especialmente as das mulheres com deficiência que sofrem uma dupla condição de opressão e vulnerabilidade. A defesa da deficiência como categoria de análise também se apresenta como uma contribuição com um importante potencial analítico e político.

Os estudos feministas da deficiência vêm também apontando importantes contribuições no que se refere à precariedade da vida, à interdependência como um elemento constituinte das relações humanas e à importância do direito ao cuidado como um princípio ético de justiça social. Para tanto, a crítica à noção moderna de independência aparece como um eixo central na produção intelectual de muitos autores. Além disso, considerando o princípio da interdependência, há uma tendência em se defender que o cuidado deve deixar de ser pensado como algo reduzido ao âmbito privado, abrangendo o âmbito público e sendo fornecido também pelas políticas sociais.

As lutas dos movimentos sociais de pessoas com deficiência se aproximam das lutas dos movimentos feministas e de lésbicas, gays, bissexuais, travestis, transexuais, transgêneros e intersexuais quando questionam o construto do corpo como um dado natural que antecede a construção dos sujeitos. Entendemos que a desnaturalização do corpo tem o potencial político de mostrar que as experiências desses grupos sociais são marcadas por relações de poder ancoradas na norma, produzindo o desvio e negando a condição de humanidade.

\section{Referências}

BACK, Laura. "Private dependence, public personhood: Rethinking 'nested obligations'”. Hypatia, v. 30 , n. 1, p. 115-131, fall 2015.

10 Revista Estudos Feministas, Florianópolis, 27(1): e48155 
BARIL, Alexandre. "Needing to acquire a physical impairment/disability: (re)thinking the connections between trans and disability studies through transability". Hypatia, v. 30, n. 1, p. 30-48, fall 2015.

BRASIL. Decreto n. 6.949, de 25 de agosto de 2009. Promulga a Convenção Internacional sobre os Direitos das Pessoas com Deficiência e seu Protocolo Facultativo, assinados em Nova York, em 30 de março de 2007. Diário Oficial da União, 26 de agosto de 2009, seção 1, p. 3.

BRASWELL, Harold. "My two moms: Disability, queer kinship, and the maternal subject". Hypatia, v. 30, n. 1, p. 234-250, fall 2015.

BUTLER, Judith. Precarious Life: The Powers of Mourning and Violence. London: Verso, 2004.

COSTA, Suely G. "Movimentos feministas, feminismos". Rev. Estud. Fem., v. 12, n. spe., p. 23-36, 2004.

CRENSHAW, Kimberlé W. "A intersecionalidade na discriminação de raça e gênero". In: W.AA. Cruzamento: raça e gênero. Brasília: Unifem, 2002. p. 7-16.

DAVIES, Hellen. "Uncomfortable connections? Conjoined sisterhood in contemporary women's writing". Contemporary Women's Writing, v. 8, n. 3, p. 409-427, nov. 2014.

DAVIS, Lennard J. "Constructing normalcy: The bell curve, the novel, and the invention of the disabled body in the nineteenth century". In: DAVIS, Lennard J. The disability studies reader. New York: Routledge, 2006. p. 22-35.

DAVY, Laura. "Philosophical inclusive design: Intellectual disability and the limits of Individual autonomy in moral and political theory". Hypatia, v. 30, n. 1, p. 132-148, 2015.

DE BOER, Tracy. “Disability and sexual inclusion”. Hypatia, v. 30, n. 1, p. 66-81, 2015.

DHANDA, Amita. "Construindo um novo léxico dos direitos humanos: Convenção sobre os Direitos das Pessoas com Deficiências". SUR - Revista Internacional de Direitos Humanos, v. 5, n. 8, p. 42-59, 2008.

DIAS, Sueli de Souza; OLIVEIRA, Maria Cláudia Santos Lopes de. "Deficiência intelectual na perspectiva histórico-cultural: contribuições ao estudo do desenvolvimento adulto". Revista Brasileira de Educação Especial, v. 19, n. 2, p. 169-182, 2013.

DINIZ, Débora. O que é deficiência. São Paulo: Brasiliense, 2007.

GARLAND-THOMSON, Rosemarie. "Integrating disability, transforming feminist theory". NWSA Journal, v. 14, n. 3, p. 1-32, 2002.

GARLAND-THOMSON, Rosemarie. "Feminist Disability Studies”. Signs, v. 30, n. 2, p. 1557-1587, 2005.

GARLAND-THOMSON, Rosemarie. "A habitable world: Harriet McBryde Johnson's 'case for my life'”. Hypatia, v. 30, n. 1, p. 300-306, 2015.

GESSER, Marivete; NUERNBERG, Adriano Henrique; TONELI, Maria Juracy Filgueiras. "A contribuição do modelo social da deficiência à psicologia social". Psicologia \& Sociedade, v. 24, n. 3, p. 557566, 2012.

GOODLEY, Dan. "Dis/entangling critical disability studies". Disability \& Society, v. 28, n. 5, p. 631644, 2013.

HALL, Kim. "New conversations in feminist disability studies: Feminism, philosophy, and borders". Hypatia, v. 30, n. 1, p. 1-12, 2015.

HERNDL, Diane Price. "Virtual cancer: BRCA and posthuman narratives of deleterious mutation". Tulsa Studies in Women's Literature, v. 32, n. 2, p. 25-45, fall 2013.

JOHNSON, Merri L. "Bad Romance: A crip feminist critique of queer failure". Hypatia, v. 30, n. 1, p. 251267, nov. 2015.

KITTAY, Eva F. "The ethics of care, dependence, and disability". Ratio Juris, v. 24, n. 1, p. 49-58, 2011.

KITTAY, Eva F. "Centering Justice on Dependency and Recovering Freedom”. Hypatia, v. 30, n. 1, p. 285-291, 2015.

KNIGHT, Amber. "Democratizing disability: Achieving inclusion (without assimilation) through 'participatory parity'”. Hypatia, v. 30, n. 1, p. 97-114, 2015. 
MCRUER, Robert; JOHNSON, Merri Lisa. "Proliferating cripistemologies: A virtual roundtable". Journal of Literary, v. 8, n. 2, p. 149-169, 2014.

MELLO, Anahi; NUERNBERG, Adriano. "Gênero e deficiência: intersecções e perspectivas". Revista Estudos Feministas, v. 20, n. 3, p. 635-655, 2012.

MILLS, Catherine. "The case of the missing hand: Gender, disability, and bodily norms in selective termination". Hypatia, v. 30, n. 1, p. 82-96, 2015.

MOLLOW, Anna. "Disability studies gets fat”. Hypatia, v. 30, n. 1, p. 199-216, 2015.

PICKENS, Therí. "Octavia Butler and the aesthetics of the novel”. Hypatia, v. 30, n. 1, p. 167-180, 2015.

PIEPMEIER, Alison. "Would it be better for her not to be born?: Down Syndrome, prenatal testing, and reproductive decision-making". Feminist Formations, v. 27, n. 1, p. 1-24, spring 2015.

PRICE, Margaret. "The bodymind problem and the possibilities of pain". Hypatia, v. 30, n. 1, p. 268284, winter 2015.

SHAKESPEARE, Tom. "The social model of disability". In: DAVIS, Lennard. The disability studies reader. New York: Routledge, 2006. p. 216-223.

SHILDRICK, Margrit. "'Why should our bodies end at the skin?': Embodiment, boundaries, and somatechnics". Hypatia, v. 30, v. 1, p. 13-29, winter 2015.

SILVER, Anita. "Becoming Mrs. Mayberry: Dependency and the right to be free". Hypatia, v. 30, n. 1, p. 292-299, winter 2015.

SIMPLICAN, Stacy Clifford. "Care, disability, and violence: Theorizing complex dependency in Eva Kittay and Judith Butler". Hypatia, v. 30, n. 1, p. 217-233, winter 2015.

ST. PIERRE, Joshua. "Distending straight - masculine time: A phenomenology of the disabled speaking body". Hypatia, v. 30, n. 1, p. 49-65, winter 2015.

TAYLOR, Ashley. "The discourse of pathology: Reproducing the able mind through bodies of color". Hypatia, v. 30, n. 1, p. 181-198, winter 2015.

THOMSEN, Carly. "The post-raciality and post-spatiality of calls for LGBTQ and disability visibility". Hypatia, v. 30, n. 1, p. 149-166, winter 2015.

Ruthie Bonan Gomes (iD 0000-0002-9873-5501

Mestre em Psicologia pela UFSC. Desenvolve trabalhos na área dos estudos sobre a deficiência na sua intersecção com educação e gênero. Bacharel em Psicologia pela Universidade de Caxias do Sul. Atua também como Psicóloga Clínica com crianças com Transtorno do Espectro do Autismo - TEA.

Universidade Federal de Santa Catarina, Departamento de Psicologia

Campus Reitor João David Ferreira Lima, s/n., Trindade

88040-900 - Florianópolis - SC - Brasil

(48) 3721-9330 - psicologia@contato.ufsc.br

rbgomes89@gmail.com

Paula Helena Lopes (iD 0000-0001-5724-7096

Mestre em Psicologia pela UFSC. Atualmente é psicóloga colaboradora do CRP 12, representante dessa entidade no Conselho Estadual de Direitos da Mulher de Santa Catarina - CEDIM, produzindo acerca das temáticas: gênero, deficiência, envelhecimento, violência psicológica, entre outras. Universidade Federal de Santa Catarina, Departamento de Psicologia Campus Reitor João David Ferreira Lima, s/n., Trindade 88040-900 - Florianópolis - SC - Brasil

(48) 3721-9330 - psicologia@contato.ufsc.br

paulahelenalopes.phl@gmail.com 
Marivete Gesser (D) 0000-0002-4091-9754

Doutora em Psicologia. Professora do Departamento de Psicologia da UFSC, onde atua no curso de Psicologia e no Programa de Pós-Graduação em Psicologia. É coordenadora do Núcleo de Estudos sobre Deficiência e integrante do Laboratório de Psicologia Escolar e Educacional. Possui interesse nos seguintes temas: estudos da deficiência, educação inclusiva, políticas públicas e direitos humanos.

Universidade Federal de Santa Catarina, Departamento de Psicologia

Campus Reitor João David Ferreira Lima, s/n., Trindade

88040-900 - Florianópolis - SC - Brasil

(48) 3721-9330 - psicologia@contato.ufsc.br

mariveteg@gmail.com

Maria Juracy Filgueiras Toneli (iD) 0000-0002-9311-5020

Doutora em Psicologia Escolar e Desenvolvimento Humano pela USP. Professora titular do Departamento de Psicologia da UFSC, onde atua no Programa de Pós-Graduação em Psicologia e é coordenadora do Núcleo de Estudos Margens. Atua na área da Psicologia, com ênfase em Psicologia Social e Institucional, com interesse nos seguintes temas: gênero, feminismos, masculinidades, saúde sexual e reprodutiva, diversidade e direitos sexuais, violências de gênero, travestilidades e transexualidades.

Universidade Federal de Santa Catarina, Departamento de Psicologia

Campus Reitor João David Ferreira Lima, s/n., Trindade

88040-900 - Florianópolis - SC - Brasil

(48)3721-9330 - psicologia@contato.ufsc.br

juracy.toneli@gmail.com

\section{COMO CITAR ESSE ARTIGO DE ACORDO COM AS NORMAS DA REVISTA}

GOMES, Ruthie Bonan; LOPES, Paula Helena; GESSER, Marivete; TONELI, Maria Juracy Filgueiras. "Novos diálogos dos estudos feministas da deficiência". Revista Estudos Feministas, Florianópolis, v. 27, n. 1, e48155, 2019.

\section{CONTRIBUIÇÃO DE AUTORIA}

Ruthie Bonan Gomes - Concepção. Coleta de dados, Análise de dados, Elaboração do manuscrito, revisão e aprovação da versão final do trabalho.

Paula Helena Lopes - Concepção. Coleta de dados, Análise de dados, Elaboração do manuscrito, revisão e aprovação da versão final do trabalho.

Marivete Gesser - Concepção. Análise de dados, Elaboração do manuscrito, revisão e aprovação da versão final do trabalho.

Maria Juracy Filgueiras Toneli - Concepção. Análise de dados, Elaboração do manuscrito, revisão e aprovação da versão final do trabalho.

\section{FINANCIAMENTO}

O presente trabalho foi realizado com apoio da Coordenação de Aperfeiçoamento de Pessoal de Nível Superior - Brasil (CAPES) - Código de Financiamento 001.

\section{CONSENTIMENTO DE USO DE IMAGEM}

Não se aplica

APROVAÇÃO DE COMITÊ DE ÉTICA EM PESQUISA

Não se aplica 


\section{CONFLITO DE INTERESSES}

Não houve conflito de interesses.

\section{LICENÇA DE USO}

Este artigo está licenciado sob a Licença Creative Commons CC-BY. Com essa licença você pode compartilhar, adaptar, criar para qualquer fim, desde que atribua a autoria da obra.

\section{HISTÓRICO}

Recebido em 13/12/2016

Reapresentado em 14/06/2018

Aprovado em 01/08/2018 